\title{
NÍVEL DE SATISFAÇÃO DOS USUÁRIOS DE SERVIÇOS DE FISIOTERAPIA: UMA REVISÃO INTEGRATIVA ${ }^{1}$
}

\author{
SATISFACTION LEVEL OF PHYSIOTHERAPY SERVICES: \\ INTEGRATIVE REVIEW
}

\section{Thais Emanuelle Gomes do Nascimento ${ }^{2}$, Maria Heloyse Martins de Lima Silva ${ }^{2}$, Lucas Sinesio Santos ${ }^{2}$, Emmily Santos Ribeiro ${ }^{2}$ e Gabriela Lopes Gama ${ }^{3}$}

\section{RESUMO}

A avaliação da satisfação dos usuários é um método de pesquisa que propicia o planejamento de ações e serviços de saúde ofertados, visando a melhoria do serviço e da qualidade do atendimento prestado. Este trabalho teve como objetivo conhecer o nível de satisfação dos usuários de serviços de fisioterapia no Brasil. Trata-se de uma revisão integrativa da literatura com consulta nas bases de dados LILACS, Scielo e PubMed, com os descritores "Satisfação do Paciente"; "Fisioterapia"; "Serviços de saúde" e "Brasil". Após a aplicação dos critérios de elegibilidade, dez artigos foram selecionados para compor a presente revisão. Nesses artigos foram utilizados seis diferentes questionários de avaliação e as principais dimensões avaliadas foram: relação com o profissional e ambiência. De modo geral, os serviços obtiveram boa avaliação na dimensão relação com o profissional, porém, na dimensão ambiência foram descritas insatisfações no que tange ao tempo de espera para o agendamento das consultas. Clínicas escolas e serviços privados foram os serviços melhor avaliados. Pode-se perceber que os usuários estão satisfeitos com os serviços de Fisioterapia que frequentam, porém, alguns fatores ainda devem ser melhorados, a fim de garantir o cuidado integral e a qualidade dos serviços, especialmente na rede pública.

Palavras-chave: Satisfação de Usuários, Avaliação do Resultado do Cuidado de Saúde, Serviços de Fisioterapia.

\section{ABSTRACT}

User's satisfaction evaluation is method that allows the planning of actions and health services offered, aiming improvements in service and quality of care. The objective was to understand physiotherapy services users' level of satisfaction in Brazil. This is an integrative literature review. The articles were searched using the descriptors "Patient Satisfaction"; "Physiotherapy"; "Health services" and "Brazil", in LILACS, Scielo and PubMed databases. After applying the eligibility criteria, ten articles were selected to compose the present review. In ten analyzed articles, six different evaluation questionnaires were used and the main dimensions assessed were relationship with professional and ambience. In general, services obtained a good evaluation in dimension relationship with professional, but in ambience dimension, deficits were still found, especially regarding the waiting time for scheduling consultations. School clinics and private services were the best evaluated. These results shows that users are satisfied with the physiotherapy services they attend in Brazil, however some factors still need to be improved in order to promote services quality, specifically in public services.

Keywords: User Satisfaction, Health Care Outcome Assessment, Physiotherapy Services.

1 Revisão Integrativa.

2 Discentes do Curso de Fisioterapia do Centro Universitário UNIFACISA. Email: thais.nascimento@maisunifacisa.com.br; maria.heloyse@maisunifacisa.com.br; lucas.sinesio@maisunifacisa.com.br; emmily.ribeiro@maisunifacisa.com.br 3 Orientadora, Doutora em Ciências da Saúde. Docente do Curso de Graduação Fisioterapia do Centro Universitário UNIFACISA. Email: gabriela.gama@maisunifacisa.com.br 


\section{INTRODUÇÃO}

$\mathrm{Na}$ atualidade, enfatiza-se que gestores de organizações e unidades de saúde devem atuar de forma a promover serviços de qualidade, sustentabilidade financeira, eficácia e eficiência. Para isso, devem-se levar em consideração as ferramentas de gestão e qualidade, para estruturar, analisar e monitorar o desempenho de uma organização (CARMO, 2018), dentre as quais podemos citar a avaliação do nível de satisfação dos usuários.

Entende-se como avaliação da satisfação de usuários a coleta e análise de dados relacionados a expectativa e percepção dos indivíduos sobre um determinado serviço consumido (ESPERIDIÃO; TRAD, 2005). Esperidião e Silva (2018) complementam que a avaliação da satisfação deve ser vista de forma ampla, englobando dados referentes ao cuidado recebido pelo paciente, com ênfase em sua experiência prévia com serviços similares.

Essa é uma importante ferramenta de gestão, tendo em vista que seus resultados produzem conhecimento quantitativo e qualitativo, além de representar uma opotunidade3 de identificação, redimensionamento e reordenação das ações e serviços, visando as necessidades reais do seu público alvo (BRASIL, 2004). Assim, a avaliação da satisfação de usuários subsidia a tomada de decisões e planejamento de ações dos gestores em saúde, sendo altos níveis de satisfação uma meta a ser atingida (BASTOS; FASOLO, 2013).

Diante dessa perspectiva, no Brasil, estudos sobre a satisfação de usuários tornaram-se cada vez mais comuns, principalmente após a redemocratização na década de 1980, quando se observou um aumento das reivindicações por serviços de qualidade (MACHADO; NOGUEIRA, 2008). $\mathrm{Na}$ atualidade, pesquisas de satisfação também são vistas como método estratégico na participação, defesa e proteção dos direitos dos usuários perante os serviços (ESPERIDIÃO E SILVA, 2018)

Diante do exposto, o presente estudo justifica-se pela importância da compreensão do nível de satisfação de usuários de serviços de fisioterapia, para melhor prestação de assistência à saúde e gerenciamento de organizações e serviços nessa área. Nesse sentido, seu objetivo geral foi avaliar o nível de satisfação dos usuários de serviço de fisioterapia no Brasil.

\section{MATERIAIS E MÉTODOS}

Trata-se de um estudo do tipo revisão integrativa da literatura realizado entre os meses de outubro e novembro de 2020. A busca de estudos foi realizada nas bases de dados: Literatura Latino-Americana e do Caribe em Ciências da Saúde (LILACS), Scientific Electronic Library Online (Scielo) e Público/editora Medline (PubMed), por meio dos descritores: serviços de saúde 
(DeCs/Mesh), fisioterapia (DeCs/Mesh), satisfação do paciente (DeCs/Mesh) e Brasil (DeCs/Mesh). Esses termos foram utilizados nos idiomas português e inglês e distribuídos de forma heterogênea para seleção dos estudos. Além disso, foi realizada uma busca manual por estudos, quando foram analisadas as referências dos artigos selecionados para revisão e das revisões da literatura já existentes sobre essa temática.

Foram considerados como critérios de inclusão: (1) artigos disponíveis na integra, (2) publicados nos idiomas: português, inglês e espanhol, (3) envolvendo usuários de serviços de fisioterapia da rede ambulatorial e (4) que avaliaram a satisfação dos usuários de serviços de fisioterapia do Brasil, sem restrição de ano de publicação. Foram excluídos artigos duplicados, do tipo revisão da literatura e aqueles que não avaliavam a satisfação de usuários de serviços de fisioterapia.

Inicialmente, a seleção dos estudos foi realizada com uso dos descritores nas bases de dados, seguida da leitura dos títulos dos artigos selecionados. Após essa etapa, os estudos que se enquadraram nos critérios de elegibilidade e no escopo da presente revisão foram selecionados para leitura na integra que embasou a seleção da amostra final.

Após a seleção dos estudos, foram extraídos dados referentes a: informações gerais (autor/ ano de publicação), população e amostra (número de participantes, idade e gênero), localização e características do setor avaliado (cidade, estado, área de atuação da fisioterapia, categoria de financiamento do serviço), instrumentos de avaliação do nível de satisfação dos usuários e principais resultados (fatores positivos/negativos e fatores correlacionados ao nível de satisfação dos usuários). Esses dados foram posteriormente apresentados em um quadro com fins comparativos.

Para análise final, os estudos selecionados foram divididos em subgrupos de acordo os diferentes eixos de avaliação do nível de satisfação (relação terapeuta/paciente, marcação de consulta, ambiente físico e conveniência, retorno e recomendação do serviço). Considerando cada eixo, foram analisados possíveis aspectos positivos e negativos que influenciaram o nível de satisfação dos usuários.

\section{RESULTADOS}

Foram identificados e selecionados dez artigos para compor a amostra final da presente revisão. Dos artigos selecionados oito foram publicados em português e dois em inglês, com anos de publicação entre 2008 e 2018. Ao todo foram avaliados 1.879 indivíduos com idade média de 54 anos, sendo 1.178 do sexo feminino.

Os resultados dos estudos analisados foram apresentados no quadro 1, no qual são identificados autor/ano, população e amostra, características do setor, instrumento utilizado para avaliação do nível de satisfação e principais resultados de cada estudo. 
Quadro 1 - Caracterização dos estudos avaliados.

\begin{tabular}{|c|c|c|c|c|}
\hline $\begin{array}{l}\text { Autor } \\
\text { (ano) }\end{array}$ & $\begin{array}{l}\text { População e } \\
\text { amostra }\end{array}$ & $\begin{array}{c}\text { Características do } \\
\text { setor }\end{array}$ & $\begin{array}{c}\text { Instrumento } \\
\text { utilizado para } \\
\text { avaliação do nível } \\
\text { de satisfação } \\
\end{array}$ & Principais resultados \\
\hline $\begin{array}{c}\text { Machado e } \\
\text { Nogueira } \\
\text { (2008) }\end{array}$ & $\begin{array}{l}376 \text { usuários } \\
\text { (235 mulhe- } \\
\text { res) Idade } \\
\text { média: } 49,5 \\
\text { anos }\end{array}$ & $\begin{array}{l}\text { Três clínicas de fisio- } \\
\text { terapia uma da rede } \\
\text { privada, uma da rede } \\
\text { pública municipal e } \\
\text { uma da rede pública } \\
\text { estadual (todas conve- } \\
\text { niadas pelo SUS) } \\
\text { Setores: ortopedia/ } \\
\text { traumatologia }(\mathrm{n}=154) \text {, } \\
\text { neurologia }(\mathrm{n}=100), \\
\text { pneumologia }(\mathrm{n}=36), \\
\text { cardiologia }(\mathrm{n}=2), \\
\text { reumatologia }(\mathrm{n}=83) \mathrm{e} \\
\text { não especificou }(=1) \text {. }\end{array}$ & $\begin{array}{l}\text { Questionário } \\
\text { próprio: } \\
\text { (Machado, 2008) }\end{array}$ & $\begin{array}{l}\text { - A maioria dos usuários relataram que os serviços pos- } \\
\text { suíam fisioterapeutas em quantidade suficiente para o } \\
\text { atendimento, confiavam no atendimento e alcançaram } \\
\text { os resultados esperados. } \\
\text { - Nas três clinicas a maioria dos usuários estiveram } \\
\text { muito satisfeitos ou satisfeitos com o atendimento } \\
\text { recebido. Nas clinicas públicas, alguns usuários } \\
\text { relataram não estar nem satisfeitos e nem insatisfeitos, } \\
\text { sendo 9,9\% na clínica municipal e 3,7\% na clínica } \\
\text { estadual. E } 3,7 \% \text { dos usuários da clínica estadual } \\
\text { estavam insatisfeitos com o atendimento. } \\
\text { - Diferenças foram observadas no tempo para chegar à } \\
\text { clínica. } \\
\text { - O tempo de espera apresentou diferenças entre os } \\
\text { serviços, quando usuários da rede pública relataram } \\
\text { maior tempo de espera em dias para início do trata- } \\
\text { mento e em minutos para início das sessões. }\end{array}$ \\
\hline $\begin{array}{c}\text { Diógenes; } \\
\text { Mendonça } \\
\text { e Guerra } \\
\text { (2009) }\end{array}$ & $\begin{array}{l}221 \text { usuários } \\
(169 \text { mulhe- } \\
\text { res) Idade } \\
\text { média: } \\
70,9 \text { anos }\end{array}$ & $\begin{array}{l}29 \text { clínicas de fisiotera- } \\
\text { pia da rede privada } \\
\text { Setores: reumatologia } \\
(\mathrm{n}=16) \text {, ortopedia/ } \\
\text { traumatologia }(\mathrm{n}=12) \text { e } \\
\text { neurologia }(\mathrm{n}=1) .\end{array}$ & $\begin{array}{l}\text { Questionário: para } \\
\text { avaliação do nível } \\
\text { de Satisfação } \\
\text { (Mendonça e } \\
\text { Guerra, 2007) }\end{array}$ & $\begin{array}{l}\text { - A maioria dos usuários se relatou satisfeitos com aten- } \\
\text { dimento. O maior índice de satisfação foi identificado } \\
\text { nos itens que englobam a interação terapeuta-paciente. } \\
\text { - Os resultados obtidos no componente de conveniência } \\
\text { (estacionamento e localização da clínica) obtiveram } \\
\text { nível de satisfação mais baixo. }\end{array}$ \\
\hline $\begin{array}{l}\text { Suda e } \\
\text { Uemura; } \\
\text { Velasco } \\
(2009)\end{array}$ & $\begin{array}{l}51 \text { usuários } \\
\text { ( } 20 \text { mulheres), } \\
\text { Idade média: } \\
47,6 \text { anos. }\end{array}$ & $\begin{array}{l}\text { Clínica Escola (Serviço } \\
\text { Público) } \\
\text { Setores: Neurologia } \\
(n=30), \text { Reumatologia } \\
(n=20) \text { e Traumatologia } \\
(n=1) .\end{array}$ & $\begin{array}{l}\text { Questionário: para } \\
\text { avaliação do nível } \\
\text { de Satisfação } \\
\text { (Mendonça e } \\
\text { Guerra, 2007) }\end{array}$ & $\begin{array}{l}\text { - Interação terapeuta-paciente, foi avaliada como boa, } \\
\text { ótima e excelente. Pontos positivos: gentileza e o respeito. } \\
\text { - Acesso e ao atendimento da recepcionista e pessoal } \\
\text { de apoio foram avaliados como bom, ótimo e excelen- } \\
\text { te. Ponto negativo: dificuldade em marcar a primeira } \\
\text { consulta. } \\
\text { - Conveniência avaliada predominantemente como } \\
\text { ótima, porém com alguma proporção ruim. } \\
\text { - Ambiente físico avaliado predominantemente como } \\
\text { ótimo, porém com alguma proporção ruim. Pontos } \\
\text { positivos: Sala do terapeuta e pontos negativos: sala } \\
\text { de espera. }\end{array}$ \\
\hline $\begin{array}{l}\text { Fréz e No- } \\
\text { bre (2011) }\end{array}$ & $\begin{array}{l}99 \text { usuários, } \\
\text { ( } 61 \text { mulheres), } \\
\text { Idade média: } \\
42,1 \text { anos. }\end{array}$ & $\begin{array}{l}5 \text { clínicas de fisiote- } \\
\text { rapia ( } 4 \text { privadas e } 1 \\
\text { pública). } \\
\text { Setores: ortopedia/ } \\
\text { traumatologia }(n=89) \text {, } \\
\text { neurologia }(n=3) \text {, } \\
\text { respiratória }(n=4), \\
\text { uroginecologia }(n=2) \text { e } \\
\text { mastologia }(n=1) .\end{array}$ & $\begin{array}{l}\text { Questionário: } \\
\text { Instrumento para } \\
\text { aferir a satisfa- } \\
\text { ção do paciente } \\
\text { com a assistência } \\
\text { fisioterapêutica na } \\
\text { rede pública de } \\
\text { saúde (Moreira et } \\
\text { al., 2007) }\end{array}$ & $\begin{array}{l}\text { - A satisfação foi caracterizada como ótima. As dimen- } \\
\text { sões relação terapeuta/paciente, acesso e espaço físico } \\
\text { apresentaram avaliação ótima e excelente. } \\
\text { - Nas dimensões marcação de consulta e ambiente } \\
\text { físico e conveniência a maioria das respostas esteve } \\
\text { entre boa e excelente. } \\
\text { - Nas dimensões relação terapeuta/ paciente, acesso e } \\
\text { espaço físico a maioria das respostas estiveram entre } \\
\text { ótima e excelente. }\end{array}$ \\
\hline
\end{tabular}




\begin{tabular}{|c|c|c|c|c|}
\hline $\begin{array}{l}\text { Gonçalves } \\
\text { et al. (2011) }\end{array}$ & $\begin{array}{l}80 \text { usuários } \\
\text { ( } 55 \% \text { mulheres). } \\
\text { Idade }>40 \\
\text { anos }\end{array}$ & $\begin{array}{l}4 \text { clínicas: uma privada, } \\
\text { uma filantrópica, } \\
\text { uma estadual e } \\
\text { uma municipal. }\end{array}$ & $\begin{array}{l}\text { Questionário: para } \\
\text { avaliação do nível } \\
\text { de Satisfação } \\
\text { (Machado, 2008) }\end{array}$ & $\begin{array}{l}\text { - Foi extremamente satisfatório a avaliação por quase } \\
\text { todos os usuários em relação ao tempo de espera para } \\
\text { o início da consulta e em média } 63 \% \text { dos usuários } \\
\text { alegaram ter tido ótima relação com o fisioterapeuta. } \\
\text { • Em geral, os usuários relataram que as clínicas ava- } \\
\text { liadas atenderam de forma satisfatórias as necessida- } \\
\text { des do tratamento. } \\
\text { - Nas clínicas municipais e estaduais os resultados } \\
\text { foram inferiores quanto ao nível de satisfação compa- } \\
\text { rado as clínicas privadas. }\end{array}$ \\
\hline $\begin{array}{l}\text { Brito; Jesus } \\
\text { e Fernandes } \\
\quad(2012)\end{array}$ & $\begin{array}{l}157 \text { usuários } \\
\text { (95 mulheres) } \\
\text { Idade média: } \\
52,6 \text { anos }\end{array}$ & $\begin{array}{l}6 \text { ambulatórios de } \\
\text { fisioterapia } \\
\text { (público ou privado } \\
\text { conveniado ao SUS). } \\
\text { Setores: ortopedia/ } \\
\text { traumatologia ( } n=124), \\
\text { neurologia (n=22), não } \\
\text { especificado (n=11) }\end{array}$ & $\begin{array}{l}\text { Parte do questio- } \\
\text { nário Programa } \\
\text { Nacional de } \\
\text { Avaliação de } \\
\text { Serviços de } \\
\text { Saúde (PNASS, } \\
\text { 2004/2005). }\end{array}$ & $\begin{array}{l}\text { - A maioria dos avaliados sente confiança no terapeu- } \\
\text { ta e sabia o nome do profissional. Pontos negativos, } \\
22,9 \% \text { não tinham recebido informações sobre seu } \\
\text { estado de saúde. } \\
\text { - Os itens relacionados a ambiência destacaram-se } \\
\text { em resultados altamente satisfatórios, já o tempo de } \\
\text { espera obteve um índice insatisfatório. }\end{array}$ \\
\hline $\begin{array}{c}\text { Almeida; } \\
\text { Nogueira e } \\
\text { Bourliatau- } \\
\text { x-Lajoine. } \\
\text { (2013) }\end{array}$ & $\begin{array}{l}95 \text { usuários } \\
\text { (62 mulheres) } \\
\text { Idade média: } \\
65 \text { anos }\end{array}$ & $\begin{array}{l}\text { Hospital Universitário } \\
\text { a Universidade Federal } \\
\text { do Estado do Rio de } \\
\text { Janeiro } \\
\text { Setor: ortopedia ( } \mathrm{n}=83) \text {, } \\
\text { neurologia }(\mathrm{n}=5) \text { e dre- } \\
\text { nagem linfática }(\mathrm{n}=7) \text {. }\end{array}$ & $\begin{array}{l}\text { Questionário: } \\
\text { SERVQUAL } \\
\text { (utilizado em } \\
\text { cinco dimensões, } \\
\text { quais sejam: } \\
\text { tangibilidade, } \\
\text { confiabilidade, } \\
\text { capacidade de } \\
\text { resposta, garantia } \\
\text { e empatia) }\end{array}$ & $\begin{array}{l}\text { - 55,3\% dos participantes acreditavam que todas as } \\
\text { dimensões do questionário tiveram o mesmo nível de } \\
\text { importância, } \\
\text { - De modo geral, os participantes apresentaram-se } \\
\text { satisfeitos. } \\
\text { - Indivíduos com mais anos de estudo apresentaram } \\
\text { níveis de satisfação mais baixos. } \\
\text { - Foi observada uma tendência do serviço de ultrapas- } \\
\text { sar as expectativas dos pacientes. } \\
\text { - Apenas os itens responsividade (desejo de ajudar os } \\
\text { usuários e fornecer um serviço rápido) e tangibilidade } \\
\text { (aparência de condições físicas e equipamentos) esti- } \\
\text { veram relacionados com o nível de satisfação. Quando } \\
\text { a responsividade contribuiu positivamente para a } \\
\text { satisfação e a tangibilidade estiveram negativamente } \\
\text { relacionados com a satisfação. }\end{array}$ \\
\hline $\begin{array}{c}\text { Carvalho; } \\
\text { Cavalvante; } \\
\text { Santos e } \\
\text { Pereira } \\
\text { (2013) }\end{array}$ & $\begin{array}{l}15 \text { usuários } \\
\text { (10 mulheres) } \\
\text { Idade média: } \\
56,7 \text { anos }\end{array}$ & $\begin{array}{l}\text { Estágio curricular - Fi- } \\
\text { sioterapia na comuni- } \\
\text { dade } \\
\text { Setores: neurologia } \\
(\mathrm{n}=8) \text {, reumatologia/ } \\
\text { ortopedia }(\mathrm{n}=4) \text {, respi- } \\
\text { ratória }(\mathrm{n}=2) \text {, angiolo- } \\
\text { gia }(\mathrm{n}=1) \text {. }\end{array}$ & $\begin{array}{l}\text { Questionário: } \\
\text { Instrumento para } \\
\text { aferir a satisfação } \\
\text { do paciente com a } \\
\text { assistência fisiote- } \\
\text { rapêutica na rede } \\
\text { pública de saúde } \\
\text { (Moreira } \\
\text { et al., 2007) }\end{array}$ & $\begin{array}{l}\text { - Grau de satisfação demonstrou íntima ligação com re- } \\
\text { lação interpessoal terapeuta/paciente e higiene/acesso. }\end{array}$ \\
\hline
\end{tabular}




\begin{tabular}{|c|c|c|c|c|}
\hline $\begin{array}{l}\text { Medeiros, } \\
\text { Costa, } \\
\text { Oliveira } \\
(2016)\end{array}$ & $\begin{array}{l}403 \text { usuários } \\
\text { ( } 220 \text { mulheres) } \\
\text { Idade média: } \\
\text { 50,5 anos }\end{array}$ & $\begin{array}{l}8 \text { clínicas de fisiotera- } \\
\text { pia: quatro privadas e } \\
\text { quatro clínicas escola. }\end{array}$ & $\begin{array}{l}\text { Instrumento } \\
\text { MedRisk } \\
\text { Instrument for } \\
\text { Measuring Patient } \\
\text { Satisfaction } \\
\text { (MRPS) }\end{array}$ & $\begin{array}{l}\text { • Em geral, pacientes mostraram-se satisfeitos com o } \\
\text { atendimento da fisioterapia. } \\
\text { - Maiores níveis de satisfação foram observados nos } \\
\text { itens que englobam relação interpessoal, e os piores } \\
\text { níveis de satisfação foram observados nos itens } \\
\text { referentes ao comprometimento do fisioterapeuta em } \\
\text { conscientizar e educar seus pacientes. } \\
\text { - Foi observada relação entre o nível de satisfação e a } \\
\text { percepção do efeito global do tratamento. } \\
\text { - O gênero também foi um fator capaz de influenciar o } \\
\text { nível de satisfação dos participantes, quando o gênero } \\
\text { masculino aponta maior satisfação. }\end{array}$ \\
\hline $\begin{array}{c}\text { Moreno; } \\
\text { Corrente; } \\
\text { Perroca; } \\
\text { Pavanelli } \\
\text { e Júnior } \\
\text { (2019) }\end{array}$ & $\begin{array}{l}382 \text { usuários } \\
\text { ( } 262 \text { mulhe- } \\
\text { res) Idade } \\
\text { média: 51,96 } \\
\text { anos }\end{array}$ & $\begin{array}{l}\text { Clínicas públicas }(\mathrm{CP}) \text {, } \\
\text { em clínicas privadas } \\
\text { conveniadas }(\mathrm{CC}) \text { e em } \\
\text { clínica-escola }(\mathrm{CE})\end{array}$ & $\begin{array}{l}\text { Questionário: para } \\
\text { avaliação do nível } \\
\text { de Satisfação } \\
\text { (Mendonça e } \\
\text { Guerra, 2007) }\end{array}$ & $\begin{array}{l}\text { - O nível de satisfação total apresentou diferenças } \\
\text { entre usuários de CE e CP, quando o primeiro grupo } \\
\text { apresentou maiores níveis de satisfação. } \\
\text { - No parâmetro interação terapeuta-paciente houve } \\
\text { diferença estatística entre os usuários avaliados entre } \\
\text { CE e CC. } \\
\text { - No que se refere a equipe de apoio houve diferença de } \\
\text { opiniões entre CE e CP. } \\
\text { - Dois parâmetros obtiveram a mesma divergência de } \\
\text { resultados entre (CE, CP) e (CC, CP), respectivamente, } \\
\text { quais foram: conveniência e ambiente físico. }\end{array}$ \\
\hline
\end{tabular}

Fonte: dados da pesquisa (2020)

Os estudos foram realizados em diferentes serviços de fisioterapia, sendo trinta e seis clínicas privadas, três clínicas privadas conveniadas ao sistema único de saúde (SUS), treze clínicas públicas, uma instituição filantrópica, sete clínicas-escolas e um hospital universitário. Os usuários avaliados realizavam atendimento fisioterapêutico nos setores de: traumatologia/ortopedia $(n=672)$, neurologia $(n=168)$, respiratória $(n=42)$, cardiologia $(n=2)$, reumatologia $(n=107)$, uroginecologia $(n=2)$ e áreas não especificadas $(\mathrm{n}=886)$.

Quanto aos instrumentos utilizados para avaliação do nível de satisfação, todos os estudos fizeram uso de questionários como método avaliativo. Mais especificamente, três artigos fizeram uso do instrumento desenvolvido e validado por Mendonça e Guerra (2007) para avaliar o nível de satisfação de usuários brasileiros em serviços de Fisioterapia, dois artigos utilizaram o questionário desenvolvido por Moreira et al. (2007), para registro de informações sobre a satisfação do paciente quanto à assistência fisioterapêutica ambulatorial no serviço público de saúde, dois artigos utilizaram questionário elaborado por Machado e Nogueira (2008), um artigo lançou mão do questionário do Programa Nacional de Avaliação de Serviços de Saúde - PNAS (BRASIL, 2004/2005); um estudo teve como subsídio para coleta de dados o questionário SERVQUAL desenvolvido por Parasuraman et al. (1990) e um artigo fez uso do Instrumento MedRisk Instrument for Measuring Patient Satisfaction (MRPS), validado por Oliveira et al. (2014).

De modo geral, os instrumentos de avaliação abordaram três dimensões (1) relação interpessoal, (2) ambiência, que envolvia questões referentes a estrutura física, higiene, estacionamento e 
(3) acesso aos serviços/confiabilidade. Dessas dimensões, questões relacionadas à relação interpessoal, sobretudo a relação terapeuta e paciente, apresentaram nível de satisfação excelente e ótimo em seis estudos (DIÓGENES; MENDONÇA; GUERRA, 2009; SUDA; UEMURA; VELASCO, 2009; FRÉZ; NOBRE, 2011; GONÇALVES et al., 2011; CARVALHO et al., 2013; MORENO et al., 2019). O único ponto que parece deixar a desejar nessa relação é o profissional não relatar informações importantes sobre o tratamento aos pacientes (BRITO; JESUS; FERNANDES, 2012).

Em contrapartida, os itens com piores níveis de satisfação estavam relacionados a ambiência: tempo de espera para agendamento de primeira consulta e entre as consultas (MACHADO; NOGUEIRA, 2008.), estacionamento e localização do serviço (DIÓGENES; MENDONÇA; GUERRA, 2009), dificuldade em marcar a primeira consulta (SUDA; UEMURA; VELASCO, 2009), conveniência e ambiente físico (MORENO et al., 2019).

Alguns dos estudos avaliados investigaram fatores relacionados ao nível de satisfação dos usuários, quando foi observado que a confiança no fisioterapeuta (BRITO; JESUS; FERNANDES, 2012), gentileza e respeito (SUDA; UEMURA; VELASCO, 2009) são considerados aspectos positivamente correlacionados com a satisfação do usuário. Além disso, o gênero e escolaridade foram fatores que surgiram como fortes influenciadores no grau de satisfação, quando homens apresentam melhores níveis de satisfação (MEDEIROS; COSTA; OLIVEIRA, 2016) e indivíduos com maior escolaridade apresentam menores níveis de satisfação (ALMEIDA; NOGUEIRA; BOURLIATAUX-LAJOINE, 2013).

De modo geral, os estudos em clínicas/serviços de Fisioterapia obtiveram conceito muito satisfatório ou satisfatório. No entanto, o trabalho de Gonçalves et al. (2011) e Moreno et al. (2019) demonstrou que clínicas-escola geralmente obtém melhor conceito quando comparadas às clínicas públicas estaduais ou municipais. Também foram notadas diferenças relevantes ao se comparar clínicas privadas, melhor avaliadas, e clínicas municipais e estaduais que apresentam conceitos de avaliação mais baixos (MACHADO; NOGUEIRA, 2008; GONÇALVES et al., 2011).

\section{DISCUSSÃO}

A presente revisão teve como objetivo conhecer o nível de satisfação de usuários dos serviços de fisioterapia no Brasil. Para isso foram realizadas pesquisas em três bases de dados em busca de estudos que avaliassem serviços de fisioterapia. Questões relacionadas a relações interpessoais foram as de melhor avaliação, enquanto questões relacionadas ao agendamento de consultas obtiveram pior avaliação pelos usuários. Além disso, fatores como gênero, escolaridade, confiança no terapeuta, respeito e gentileza estiveram diretamente relacionados com o nível de satisfação dos usuários.

No que diz respeito aos métodos de avaliação descritos pelos estudos selecionados, todos os autores optaram pelo uso de questionários. Tal fato reforça os achados de Esperidião e Trad (2005) ao 
demonstrarem que o método quantitativo com escalas e questionários, utilizado no Brasil desde 1995, vem se tornando cada dia mais popular quando se procura investigar a satisfação dos indivíduos em relação aos serviços de saúde. Trad et al. (2009), destacam ainda que existem outros métodos para complementar tais avaliações como abordagens de caráter qualitativo e entrevista. Entretanto, mesmo tendo em comum o uso de questionários para análise de dados, seis tipos de questionários diferentes foram utilizados pelos estudos aqui selecionados. Essa diversidade pode comprometer a comparação entre os achados, o que sugere a necessidade de elaboração de um referencial próprio de pesquisa de satisfação para os serviços de saúde brasileiros (ESPERIDIÃO; TRAD, 2005).

As dimensões avaliadas na maioria dos estudos que fizeram parte da presente revisão (relação profissional/paciente, ambiência e acesso) estão de acordo com estudos que avaliam o nível de satisfação em outros serviços de saúde. Os elementos que compõem essas dimensões estão de acordo com a teoria da atitude descrita por Esperidião e Trad (2005) e Pelz (1982), onde a satisfação é entendida como uma avaliação positiva ou negativa realizada pelo usuário de determinado serviço de saúde, avaliando aspectos como acesso, eficácia, conveniência, dentre outros elementos considerados como atributos do serviço.

Apesar de todos os serviços avaliados terem conceito muito satisfatório ou satisfatório por seus usuários, clínicas-escola geralmente obtiveram melhores conceitos quando comparadas às clínicas públicas estaduais ou municipais. Esses achados vão ao encontro de achados prévios, segundo os quais pacientes atendidos em clínicas-escola se sentem confortáveis e acolhidos, por serem atendidos por estagiários (VIANA et al., 2014) e que, não só voltariam caso precisassem, mas também indicariam o serviço para familiares e amigos (GUZZO; FASSICOLO; 2011). Esses achados podem ser explicados pelo esforço diário dos estagiários em ampliar seus conhecimentos sobre as diversas patologias, além de proporcionar um atendimento individualizado, ético e de qualidade (SANTOS; BICALHO; BORGES, 2012).

No que se refere a comparação entre os serviços, foram observadas diferenças entre clínicas privadas, melhor avaliadas, a clínicas municipais e estaduais, pior avaliadas. Santos, Ramos e Souza (2011) atribuem a pior avaliação dos serviços públicos ao pensamento popular de que o serviço privado apresenta superioridade quando comparado ao serviço público. Esses autores enfatizam ainda que, o resultado do serviço não está ligado apenas aos recursos financeiros, mas também, a disponibilidade do profissional em prestar o serviço. Sugere-se ainda que, no Brasil, a grande demanda pela rede pública de assistência à saúde, o número reduzido de serviços disponíveis e, consequente, o longo tempo de espera para assistência. podem representar aspectos negativamente relacionados aos níveis de satisfação nos serviços públicos.

O gênero e escolaridade foram fatores influenciadores no grau de satisfação dos usuários de serviços de fisioterapia no Brasil. Tal fato, pode estar associado a possível relação entre escolaridade, condições socioeconômicas e nível de conhecimento da qualidade do serviço a ser prestado, 
possibilitando maior senso crítico em indivíduos com maiores níveis de escolaridade (TRAVASSOS; VIACAVA, 2007).

No que diz respeito ao gênero, Barreto, Arruda e Marcon (2015) afirmam que um menor quantitativo de homens busca por serviços de saúde, em geral, apenas de forma emergencial. Assim, o curto período de tempo e o caráter emergencial da assistência à saúde podem impossibilitar homens de avaliar de forma crítica o serviço prestado. Essa, entretanto, é apenas uma hipótese que não pode ser avaliada com base em nenhum dos estudos selecionados, devendo ser averiguada por estudos futuros.

Os estudos demonstraram que a inter-relação terapeuta/paciente é considerada ótima quando há confiança no fisioterapeuta, além de gentileza e respeito. Tais dados corroboram com o estudo de Schimithet et al. (2011) segundo o qual compromisso, responsabilidade, cumplicidade e sensibilidade são fatores primordiais para a geração de um vínculo satisfatório entre usuário e profissional. Nessa relação, todavia, existe um ponto que foi avaliado negativamente pelos estudos analisados: o fato do profissional deixar de relatar aos pacientes informações importantes sobre o tratamento. Esses achados corroboram com estudos prévios, segundo os quais profissionais de saúde não têm o hábito de fornecer informações referentes ao diagnóstico e tratamento aos pacientes ou familiares, demonstrando a inabilidade de alguns profissionais em lidar com o sofrimento humano, (MENDES; LUSTOSA; ANDRADE, 2009).

Dentre as dimensões avaliadas como ruins, destaca-se o tempo de espera para agendamento da primeira consulta, tempo de espera antes do início da consulta e espera entre as consultas seguintes. Brito, Jesus e Fernandes (2012) afirmam que o tempo de espera é um grave problema que compromete o acesso integral do paciente ao serviço de saúde, cabendo aos responsáveis pelo serviço propor novas medidas e modelos organizacionais de administração do tempo que reduzam a espera tangente aos atendimentos. Assim, os dados do presente estudo sugerem a real necessidade de investimentos na ambiência dos serviços de fisioterapia do Brasil, a fim de ampliar o nível de satisfação de seus usuários.

Apesar da importância do tema investigado e das relevantes informações geradas pelo presente estudo, o mesmo apresenta algumas limitações como a ausência de avaliação quantitativa dos estudos selecionados e de um segundo revisor para seleção e análise dos estudos. Essas limitações sugerem a realização de estudos futuros de caráter experimental e de revisão a fim de complementar os achados disponíveis na literatura sobre o tema.

\section{CONCLUSÃO}

A partir dos resultados da presente revisão foi possível identificar que, de modo geral, usuários estão satisfeitos com os serviços de Fisioterapia que frequentam, principalmente no que se refere a relação com os profissionais. A ambiência, por sua vez, foi avaliada como deficiente. Vale ainda 
salientar que clínicas-escola foram os serviços mais bem avaliados, o que demonstra que os usuários se sentem confortáveis em serem atendidos por estagiários. Por fim, se observou que ainda há uma cultura de subestimação dos serviços públicos em detrimento dos serviços privados.

\section{REFERÊNCIAS}

ALMEIDA, R. S.; NOGUEIRA, L. A. C.; BOURLIATAUX-LAJOINE, S. Análise do nível de satisfação do usuário em um serviço público de fisioterapia. Brazilian Journal of Physical Therapy. v. 17, n. 4, p. 328-335, 2013.

BARRETO, M.S. ARRUDA, G.O. MARCON, S.S. Como os homens adultos utilizam e avaliam os serviços de saúde. Revista Eletrônica de Enfermagem. v. 17, n. 3, 2015 jul./set.

BASTOS, G. A. N.; FASOLO, L. R. Fatores que influenciam a satisfação do paciente ambulatorial em uma população de baixa renda: um estudo de base populacional. Revista Brasileira de Epidemiologia. Porto Alegre, v. 16, n. 1, 2013.

BRITO, T. A.; JESUS, C. S.; FERNANDES, M. H. Fatores associados à satisfação dos usuários em serviços de fisioterapia. Revista Baiana de Saúde Pública. v. 36, n. 2, p. 514-526, 2012.

BRASIL. Ministério da Saúde. Programa Nacional de Avaliação de Serviços de Saúde - PNASS. Brasília. Ed. 2004-2005.

BRASIL. Ministério da Saúde. PNASS: Programa Nacional de Avaliação de Serviços de Saúde. Brasília: Ministério da Saúde, 2015. 64 p.

CARMO, C. M.; Gestão assistencial da fisioterapia hospitalar: indicadores. São Paulo, 2018.

CARVALHO, V. L. C. et al. Satisfação dos pacientes atendidos no estágio curricular de fisioterapia na comunidade. Fisioterapia e Pesquisa. v. 20, n. 4, p. 330-335, 2013.

COSTA, C. R. S.; MONTAGNA, E.; A formação acadêmica do fisioterapeuta para sua atuação na gestão em saúde. ABCS Health. Santo André, v. 40, n. 3, p. 252-256, 2015. 
DIOGENES, T. P. M.; MENDONÇA, K. M. P. P.; GUERRA, R. O. Dimensões da satisfação do paciente idoso brasileiro com a fisioterapia ambulatorial. Revista brasileira de fisioterapia. São Carlos. v. 13, n. 4, p. 301-307, 2009.

ERCOLE, F. F.; MELO, L. S.; ALCOFORADO, C. L. G. C. Revisão Integrativa versus Revisão Sistemática. Revista Mineira de Enfermagem. Minas Gerais, v. 18, n. 1, p. 260, 2014.

ESPERIDIÃO, M. A.; SILVA, L. M. V. A satisfação do usuário na avaliação de serviços de saúde: ensaio sobre a imposição de problemática. Saúde Debate. Rio de Janeiro, v. 42, número especial 2, p. 331-340, outubro 2018 .

ESPERIDIÃO, M. A.; TRAD, L. A. B. Avaliação de Satisfação de Usuários. Ciência \& Saúde Coletiva. v. 10, p. 303-312, 2005.

FONSECA, J. M. A. et al. A fisioterapia na atenção primária à saúde: Uma revisão integrativa. Revista Brasileira de Promoção da Saúde. Fortaleza, v. 29, n. 2, p. 288-294, 2016.

FREZ, A. R.; NOBRE, M. I. R. S.; Satisfação dos usuários dos serviços ambulatoriais de fisioterapia da rede pública. Fisioterapia em Movimento. Curitiba, v. 24, n. 3, p. 419-428, jul./set. 2011.

GONÇALVES, J. R. et al. Avaliação da satisfação dos pacientes submetidos à intervenção fisioterapêutica no município de Campo Maior, PI. Fisioterapia em Movimento. Curitiba, 2011, v. 24, n. 1, p. 47-56. 2011.

GUZZO, S.; FASSICOLO, C. E. Avaliação da satisfação dos usuários de serviços de fisioterapia na clínica escola de pesquisa e atendimento em fisioterapia (CEPAF) da Universidade do Oeste de Santa Catarina (UNOESC). Lecturas: Educación Física y Desportes. Ano 16, n, 163, Buenos Aires, dezembro de 2011.

MACHADO, N. P.; NOGUEIRA, L. T. Avaliação da satisfação dos usuários de serviços de Fisioterapia. Revista Brasileira de Fisioterapia. São Carlos, v. 12, n. 5, p. 401-408, 2008.

MEDEIROS, F. C. et al. Satisfação de pacientes que recebem cuidados fisioterapêuticos para condições musculoesqueléticas: um estudo transversal. Fisioterapia em Pesquisa. v. 23, n. 1, p. 105-110, 2016. 
MENDES, J. A.; LUSTOSA, M. A.; ANDRADE, M. C. M. Paciente terminal, família e equipe de saúde. Revista da Sociedade Brasileira de Psicologia Hospitalar. v.12 n.1 Rio de Janeiro, jun. 2009.

MENDONÇA, K. M. P. P.; GUERRA, R. O. Desenvolvimento e validação de um instrumento de medida da satisfação do paciente com a fisioterapia. Revista Brasileira de Fisioterapia. São Carlos, v. 11, n. 5, p. 369-376, set./out. 2007.

MISHINA, S. M. Satisfação do usuário sob a perspectiva da responsividade: estratégia para análise de sistemas universais? Revista Latino-americana de Enfermagem. São Paulo, v. 24, p. 2674, 2016.

MORENO, B. G. D. et al. Avaliação da satisfação dos usuários de fisioterapia em atendimento ambulatorial. Fisioterapia em Pesquisa. v. 26, n. 3, p. 322-328, 2019.

MOREIRA, C. F. et al. Instrumento para aferir a satisfação do paciente com a assistência fisioterapêutica na rede pública de saúde. Fisioterapia E Pesquisa. v. 14, n. 3, p. 37- 43, 2007.

NAVES, C. R.; BRICK, V. S. Análise quantitativa e qualitativa do nível de conhecimento dos alunos do curso de fisioterapia sobre a atuação do fisioterapeuta em saúde pública. Ciência e Saúde Coletiva. São Paulo, v. 16, n. 1, p. 1525-1534, 2011.

OLIVEIRA, N. F. C. et al. Measurement Properties of the Brazilian Portuguese Version of the MedRisk Instrument for Measuring Patient Satisfaction With Physical Therapy Care. Journal of Orthopaedic \& Sports Physical Therapy. v. 44, n. 11, p. 879-89, 2014.

PARASURAMAN, A. et al. SERVQUAL: A multiple-item scale for measuring consumer perceptions of service quality. Journal of Retailing. v. 64, n. 1, p. 12-40, 1990.

LINDER-PELZ, S. Toward a theory of patient satisfaction. Social Science \& Medicine. n. 16, p. 577-582, 1982.

SANTOS, E. C.; RAMOS, A. S.; SOUSA, E. A. Atendimento pediátrico humanizado, reação da criança e satisfação dos pais no serviço público e privado de fisioterapia respiratória. Estação Científica (UNIFAP). Macapá, v. 1, n. 2, p. 69-84, 2011. 
SANTOS, J. B.; BICALHO, K. A.; BORGES, M. B. S. Características e nível de satisfação dos pacientes atendidos na clínica-escola de fisioterapia da Universidade Católica de Brasília. EFDesportes. com, Revista Digital. Ano 17, n, 171, Buenos Aires, agosto de 2012.

SCHIMITH, M. D. Et al. Relações entre profissionais de saúde e usuários durante as práticas em saúde. Trabalho, Educação e Saúde, Rio de Janeiro, v. 9, n. 3, p. 479-503, nov. 2011/fev. 2012.

SUDA, E. Y.; UEMURA, M. D.; VELASCO, E. Avaliação da satisfação dos pacientes atendidos em uma clínica-escola de Fisioterapia de Santo André, SP. Fisioterapia e Pesquisa. São Paulo, v. 16, n. 2, p. 126-31, abr./jun. 2009.

TRADE, L. A. B. Grupos focais: conceitos, procedimentos e reflexões baseadas em experiências com o uso da técnica em pesquisas de saúde. Physis Revista de Saúde Coletiva. Rio de Janeiro, v. 19, n. 3, p. 777-796, 2009.

TRAVASSOS, C. VIACAVA, F. Acesso e uso de serviços de saúde em idosos residentes em áreas rurais, Brasil, 1998 e 2003. Cadernos de Saúde Pública. v. 23 n. 10. Rio de Janeiro/outubro, 2007.

VIANA, J. R. S. et al. Avaliação da satisfação com a fisioterapia de pacientes atendidos em uma clínica escola de Maringá - PR. Revista UNINGÁ Review. v. 17, n. 2, p. 16-21, 2014. 